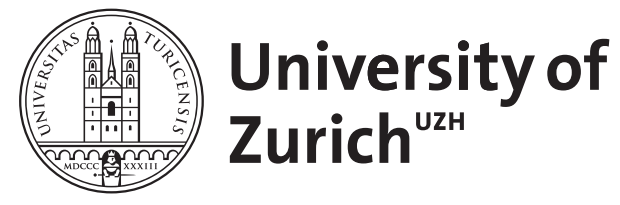

Zurich Open Repository and Archive

University of Zurich

University Library

Strickhofstrasse 39

CH-8057 Zurich

www.zora.uzh.ch

Year: 2015

'Erbauung' - und darüber hinaus. Spannungen im

volkssprachlich-lateinischen Spätmittelalter. Mit Überlegungen zu Gertruds von Helfta 'Exercitia spiritualia'

Köbele, Susanne

DOI: https://doi.org/10.1515/bgsl-2015-0038

Posted at the Zurich Open Repository and Archive, University of Zurich

ZORA URL: https://doi.org/10.5167/uzh-120262

Journal Article

Published Version

Originally published at:

Köbele, Susanne (2015). 'Erbauung' - und darüber hinaus. Spannungen im volkssprachlich-lateinischen Spätmittelalter. Mit Überlegungen zu Gertruds von Helfta 'Exercitia spiritualia'. Beiträge zur Geschichte der deutschen Sprache und Literatur, 137(3):420-445.

DOI: https://doi.org/10.1515/bgsl-2015-0038 


\title{
Susanne Köbele
}

\section{\Erbauung - - und darüber hinaus}

\section{Spannungen im volkssprachlich-lateinischen Spätmittelalter. Mit Überlegungen zu Gertruds von Helfta ıExercitia spiritualia،}

DOI 10.1515/bgsl-2015-0038

\begin{abstract}
The following paper argues for a revision of the notion of sedification « in the Middle Ages. By comparing exemplary texts (including the Exercitia spiritualia`, which are attributed to Gertrude the Great), it shows the ramifications, tensions and textual productivity in the medieval usage of the term sedification implementation. In addition to the subsequent essay by Burkhard Hasebrink, this paper attempts to describe the different, yet similarly contradictory claims of sedification in the tension between (self)disciplining and transgression.
\end{abstract}

\section{I. sancta simplicitas. Denkfallen}

Die Frage nach Konzepten des `Erbaulichen « im Mittelalter führt in weitreichende Problemdimensionen religiöser Pragmatik und Ästhetik. Bekannt und vielfach beklagt ist die notorische Unschärfe des `Erbauungs`-Begriffs insbesondere im Bereich der Literaturwissenschaft, die mit der allgemeinen Nomenklatur (〉Erbauungsliteratur`) in der Regel einen Dachbegriff sucht für die grundsätzliche Heteronomie religiöser Texte und ihr Unbehagen an dieser historischen Abstraktion gern mit dem Zusatz des ısogenannt` Erbaulichen artikuliert. ${ }^{1}$ In der mediävisti-

1 Vgl. die funktionsanalytischen und forschungskritischen Überlegungen bei Ute MenneckeHaustein: [Art.] 'Erbauungsliteratur<, in: Literatur Lexikon, Bd. 13, 1992, S. 233-239. »Was `Erbauung، inhaltlich bedeute, wird von der Literaturwissenschaft als bekannt oder notorisch unbekannt vorausgesetzt« (S. 233). Dazu auch: Wolfgang Brückner: Thesen zur Struktur des sogenannten Erbaulichen, in: ders. [u. a.] (Hgg.): Literatur und Volk im 17. Jahrhundert. Probleme populärer Kultur in Deutschland, Teil 2, Wiesbaden 1985 (Wolfenbütteler Arbeiten zur Barockforschung 13), S. 499-507.

Prof. Dr. Susanne Köbele: Universität Zürich, Deutsches Seminar, Schönberggasse 9, CH-8001 Zürich, E-Mail: susanne.koebele@ds.uzh.ch 
schen Literaturwissenschaft dient `Erbauung in den meisten Fällen als Sammelbegriff für ein möglichst breites Spektrum religiöser (seelsorgerischer) Gebrauchsfunktionen zwischen Heilsverkündigung, Paränese, Exegese und religiöser delectatio, mit dem übergreifenden Ziel der Konsolidierung des Glaubens. ${ }^{2}$ Dabei steht der Lakonismus der Begriffsverwendung quer zur unüberschaubaren Vielfalt der mit `Erbauung ‘ angezielten Phänomene, deren immanente Spannungen affektive, spekulative, moralische und ästhetische Eigendynamiken - leicht übersehen werden.

Der folgende Beitrag plädiert für eine Revision des spezifisch mittelalterlichen `Erbauungs<-Begriffs. Er skizziert ein offenes Forschungsfeld: die Vielschichtigkeit im Begriffsgebrauch und in der Umsetzung von `Erbauung im Mittelalter, und kann hier nicht mehr sein als ein erster, auf kleine Textausschnitte begrenzter Vorstoß.

Als metaphorisch fundierter Begriff ist `Erbauung` (lat. aedificatio) von den christlichen Anfängen an komplex angelegt. Bereits innerbiblisch kann `Erbauung ‘ ganz unterschiedliche Zeit- und Zeichenperspektiven vermitteln, im Spannungsfeld von Offenbarung und Auslegung, Verheißung und Erfüllung. Gott schließt mit Abraham den Bund, das >Haus` Israel aufzubauen (2 Sam 7,27), was exegetisch auch auf den Tempel- oder Archebau bezogen wird, der dann im Bau der Kirche (der Gemeinde wie des Einzelnen) und schließlich endzeitlich im Bau des himmlischen Jerusalem Erfüllung finde. ${ }^{3}$ In der paulinischen Tradition bezeichnet >Erbauung ‘ den Vorgang des Aufbaus der Kirche als Gemeinschaft in charakteristischer Wechselseitigkeit von individueller und kollektiver Stärkung des Glaubens. In diesem reziproken Sinn, zwischen den Polen Ekklesiologie und Seelsorge wechselnd, begegnet der Begriff schon bei Paulus mit dem Bild von der Kirche als >Haus`, dessen lebendige Steine die Christen sind, propter quod consolamini invicem et aedificate alterutrum sicut et facitis (1 Th 5,11). Einer serbaue den anderen, und zwar durch sein Reden und Handeln, idealiter in exemplarischer Kongruenz von verba und vita. Hinzukommt eine charakteristische Inversion aktiver und passiver Vorgänge, wenn das religiöse Subjekt, etwa als Autor oder Schreiber eines serbauenden Textes, sich in dieser textproduktiven Rolle auch selbst erbauen (lassen) will und so als Subjekt und Medium religiöser Erbauung zugleich auftritt. Mittelalterliche Texte reagieren auf diese Situation mit spezifischen Textrahmungen,

2 Exemplarisch seien genannt: Wieland Schmidt: Zur deutschen Erbauungsliteratur des späten Mittelalters, in: Kurt Ruh (Hg.): Altdeutsche und altniederländische Mystik, Darmstadt 1964 (WdF 23), S. 437-461; Dietrich Schmidtke: Studien zur dingallegorischen Erbauungsliteratur des Spätmittelalters am Beispiel der Gartenallegorie, Tübingen 1982.

3 Vgl. Hans Pohlmann: [Art.] `Erbauung`, in: RAC, Bd. 5, 1962, Sp. 1043-1070. 
raschen Sprechaktwechseln oder Subjekt-Umbesetzungen, so etwa die Einleitung zur zweiten ১Übung، aus Gertruds von Helfta `Exercitia spiritualiaı: utere hoc exercitio, orans deum, ut te sibi in amoris omniumque virtutum aedificet monasterium. ${ }^{4}$ Dabei spielt es konzeptionell, bildlogisch und wirkungsästhetisch durchaus eine Rolle, ob das Haus, als das die liebende Einzelseele für Gott und von Gott erbaut werden soll, Fenster haben darf (beispielsweise als Einlass für die Offenbarung) ${ }^{5}$ oder verschiedene Zimmer, ob das Herz als Tempel, Kloster, Burg, als Küche (mit dem Heiligen Geist als Koch, wie bei Mechthild von Hackeborn ${ }^{6}$ ), als Grabmal oder exklusives Brautgemach vorgestellt ist. Ist nur vom Erbauen die Rede oder auch vom Wohnen, vom Wohnen des Menschen in Gott oder vom Wohnen Gottes im Menschen?

Hinzukommen Überschneidungen mit parallelen Bildtraditionen. Denn für den angezielten Sachverhalt wechselseitiger Glaubensstärkung kann das Bildfeld der Architektur (`Erbauen eines Hauses) gleitend übergehen in das Bildfeld der Agrikultur (`Bebauen`: Pflanzen, Wachsen, Ernten, Nähren) ${ }^{7}$ mit unterschiedlichen Referenzbereichen, auch mit unterschiedlichen Axiologien. Bildlogisches Tertium zwischen `Erbauen ‘ und `Bebauen` ist $\mathrm{u}$. a. die gängige Vorstellung der Seele als Kloster der >lebendigen Liebe, die den Mittelpfeiler als Baum der Weisheit zum Blühen bringen und auf engstem Raum offene Kohärenzen produzieren kann, über gleitende Wechsel zwischen Bild- und Bedeutungsebene, wie sie im allegorisch-exegetischen Schrifttum der Zeit wohl kaum als Bildbrüche wahrgenommen wurden, eher als Konnotationen (simul sunt c o n sideranda,[...] per co m parationem), als eine Art kontemplative Simultanwahrnehmung (contuitus), die den Affekt des Staunens (admiratio) erzeuge. ${ }^{8}$ Als Kloster der lebendig

4 'Bete Du, wie ich es vorschlage, damit Gott sich aus dir - und durch meine Gebetsübung - ein Kloster der Liebe und aller Tugenden bauen kann.` Gertrude d'Helfta: Euvres spirituelles Tome 1: Les Exercices. Texte latin. Introduction, traduction et notes par Jacques Hourlier et Albert Schmitt, Paris 1967 (Sources Chrétiennes 127), II,4 f. Vgl. außerdem die Ausgabe Gertrud von Helfta: Exercitia spiritualia. Geistliche Übungen. Lateinisch und deutsch, hg., übersetzt und kommentiert v. Siegfried Ringler, Hamburg 2001. - Ich komme unten auf diese Stelle zurück.

5 Vgl. Kurt Ruh: Gertrud von Helfta. Ein neues Gertrud-Bild, in: ZfdA 121 (1992), S. 1-20, hier S. 12.

6 Vgl. Kurt Ruh: Geschichte der abendländischen Mystik, Bd. 2: Frauenmystik und Franziskanische Mystik der Frühzeit, München 1993, S. 311.

7 Vgl. Friedrich Ohly: Cor amantis non angustum. Vom Wohnen im Herzen, in: ders. (Hg.): Schriften zur mittelalterlichen Bedeutungforschung, Darmstadt 1977, S. 128-155, bes. 136-138. Christoph Burger: Aedificatio, fructus, utilitas. Johannes Gerson als Professor der Theologie und Kanzler der Universität Paris, Tübingen 1986; Hannes Böhringer: [Art.] >Bauen`, in: Ralf Konersmann (Hg.): Wörterbuch der philosophischen Metaphern, 2. Aufl., Darmstadt 2008, S. 34-46.

8 Dum ergo haec per se singillatim consideras, habes unde veritatem contempleris; dum haec ad invicem c o nfers, habes unde in admirationem altissimam suspendaris: et 
liebenden Seele können die Seelenkräfte daher ohne weiteres sowohl als Haus Gottes (domum dei) gelten wie parallel auch ıgrünen, blühen und kräftig zu würdigen Früchten heranwachsen ${ }^{9}$, im günstigsten Fall als ein beide Bildbereiche engführender ummauerter Paradiesgarten (virtutum paradisum). Damit liegt auf der Hand, dass immanente Spannungen des christlichen Erbauungskonzepts auch als >figuratives Wissen ' wahrgenommen zu werden verdienen: als Konzepte auf der Grenze von Begriffs- und Bildlogik, von prägnantem Terminus technicus und allegorischer dilatatio. Im Sonderfall der Anwendung der Erbauungs-Metapher auf die Heilige Schrift können darüber hinaus mehr oder weniger verdeckte Hierarchien zur Geltung kommen: Die mittelalterliche Exegese - als geistige Architektur systematisch vor den Augen des Lesers entworfen von den Victorinern - >überbaut` die Bibel mit dem vierfachen Schriftsinn, mit historia als Fundament, allegoria als Mauern, tropologia als Inneneinrichtung und anagogia als Dach, ${ }^{10}$ was eine nicht immer gleichmäßig transparente Hierarchie von Oben und Unten, Außen und Innen suggeriert und auch eine offene Dynamik von Teil und Ganzem herstellt. ${ }^{11}$ Und bei alldem bleibt in serbaulichen` Texten der Verdacht unangemessener Selbst-Erbauung virulent, weswegen häufig ein Grundmisstrauen gegenüber heilseuphorischen Situationen (meine Seele will sich wohl

ideo, ut mens tua per admirationem in admirabilem ascendat contemplationem, ha e c s i m u $\mathrm{l}$ sunt consideranda. Bonaventura: Itinerarium mentis in Deum. Der Pilgerweg des Menschen zu Gott. Lateinisch-deutsch, übersetzt u. erläutert v. Marianne Schlosser. Mit einer Einleitung v. Paul Zahner, Münster 2004 (Theologie der Spiritualität. Quellentexte 3), VI,3 f., S. 98. Der Text entspricht der Quaracchi-Ausg.: Opera omnia, Bd. 5: Opuscula varia theologica. Studio et cura PP. Collegii a S. Bonaventura [...] Quaracchi 1891 (Doctoris Seraphici S. Bonaventurae S. R. E. Episcopi Cardinalis opera omnia 5), S. 293-316. Über die rekurrenten Wortbildungen mit con- lohnte in diesem Zusammenhang weiteres Nachdenken.

9 Vgl. Gertrude d'Helfta: Euvres spirituelles [Anm. 4], VII,657 f., 664 ff. (Eia o deus vitae meae, in te revireat, refloreat, et in fructus dignos convalescat vita mea) und $692 \mathrm{f}$.

10 Vgl. Henning Brinkmann: Die Exegese als Bau, in: ders. (Hg.): Mittelalterliche Hermeneutik, Darmstadt 1980, S. 132-140, mit Bezug auf Hugo von St. Victor, der mit Exegese als einem spirituellen Gebäude auf ein kontemplatives Ganzes zielt, in dem gleichzeitig alle Elemente des Glaubens vorhanden seien, anders als in der älteren, von Einzelwort zu Einzelwort springenden Exegese (vgl. S. 132 f.). Auch Richards von St. Victor Exegese ist um peinliche Detailgenauigkeit bemüht, entwirft aber zugleich den Bau des Ganzen (compositio) weiträumig als Totalität: Richards Auslegung der Ezechiel-Visionen baut den Tempel akribisch genau auf und gibt sogar Baupläne und Zeichnungen mit (vgl. S. 137 f.). Dazu, mit reicher Literatur, Aleksandra Prica: Heilsgeschichten. Untersuchungen zur mittelalterlichen Bibelauslegung zwischen Poetik und Exegese, Zürich 2010, v. a. S. 84-97.

11 Vgl. Ralf Konersmann: Vorwort. Figuratives Wissen, in: ders. [Anm. 7], S. 34-46. 
selber trösten? $)^{12}$ vorbeugend mitbesprochen wird - wie schon der erste Korintherbrief prophetisches Charisma, das die Gemeinde erbauen will, von bloßer Zungenrede unterscheidet, die nur sich selbst erbauen will. ${ }^{13}$

Wenn `Erbauungsliteratur demnach Texte umfasst, »die dem Christen zur Bekräftigung im Glauben, zur Vergegenwärtigung der Heilsgeschichte und zur Anleitung in christlicher Lebensführung dienen ${ }^{14}$ wollen, demonstriert bereits diese knappe Definition, dass die Kernbestimmung von `Erbauung auf ein sowohl intellektuelles wie moralisches Instruieren und Affizieren hinausläuft, das vor dem Hintergrund der in der Definition genannten Wirkungsabsichten auch textpoetologische Auswirkungen haben müsste. Die Lage ist ziemlich komplex. Denn seit der Spätantike gelten die zu erbauenden religiösen Affekte (zentral: Glaubensstärke, Gottesliebe, Heilszuversicht) zugleich als theologische Tugenden (fides, caritas, spes), die zudem Wissen und Erkenntnis disponieren und darüber hinaus im Sinn christlicher delectatio auch durch ästhetische Effekte zum Modus von Heilsvergegenwärtigung werden. ${ }^{15}$ Spannungen zwischen ästhetischen, pastoraltheologischen und hermeneutischen Erbauungsansprüchen sind damit vorprogrammiert. Sie gehen nicht auf in der religiösen Umbesetzung der traditionellen rhetorischen Funktionskategorien (docere, movere, delectare). Was, wenn das Erbauungsziel der vielfältig (ungeduldig, eifersüchtig, furchtsam) glaubenden, liebenden und hoffenden Seele ausgerechnet ein seinfacher Affekt ist (affectus simplex), der weder ein einfältiger sein will, noch ein traditionell nach Seelenteilen gemischter oder Tugenden gestufter

12 Mit Bezug auf Mechthild von Hackeborn Ruh [Anm. 6], S. 307. In diesem Fall löst eine göttliche Stimme den Selbsttröstungsverdacht auf.

13 Vgl. 1 Cor 14,3 f.: nam qui prophetat hominibus loquitur aedificationem et exhortationem et consolationes qui loquitur lingua semet ipsum aedificat. Einschlägig dazu, für den Kontext spätmittelalterlicher Mystik, Werner Williams: Diese ding sint dennoch nit ware zeichen der heilikeit. Zur Bewertung mystischer Erfahrungen im 15. Jahrhundert, in: Zeitschrift für Literatur und Linguistik 20 (1990), S. 61-71.

14 Susanne Schedl u. Dietz-Rüdiger Moser: [Art.] `Erbauungsliteraturı, in: ${ }^{2}$ RLW, Bd. 1, 1997, S. 484-488, hier S. 484; zu diesem offenen Spektrum zwischen Mahnen und Trösten außerdem Mennecke-Haustein [Anm. 1]. Thomas von Aquin koppelt terminologisch die Verkündigungsfunktion der Predigt (praedicatio als erbauliche instructio qua Schriftauslegung) eng an prophetische Rede (exponere et exhortari, quod est prophetare, Summa theologica III, q. 67 a. 1, ad 1); vgl. dazu - mit Blick auf Funktionsverschiebungen der Predigt bei Eckhart - Burkhard Hasebrink: Formen inzitativer Rede bei Meister Eckhart. Untersuchungen zur literarischen Konzeption der deutschen Predigt, Tübingen 1992 (Texte und Textgeschichte 32), S. 3-8.

15 Vgl. Reinhard Herzog: Exegese - Erbauung - Delectatio. Beiträge zu einer christlichen Poetik der Spätantike, in: Walter Haug (Hg.): Formen und Funktionen der Allegorie. Symposion Wolfenbüttel 1978, Stuttgart 1979 (Germanistische Symposien. Berichtsbände 3), S. 52-69. 
Affekt, sondern eben seinfach`, >rein` (mens pura) und sumfassend` (tota anima)? Zwar kann Erbauung aspekt- bzw. gattungsabhängig mehr Mahnung (adhortatio), mehr Tröstung (consolatio) intendieren, häufig auch beides zugleich. ${ }^{16}$ Doch wie lässt sich der mit der Erbauung angezielte affectus simplex vermitteln mit der augustinisch geprägten anthropologischen Grundvorstellung einer anima hierarchizata, zumal vor dem Hintergrund einer Fülle verschiedener, gleitend synonymischer Inneninstanzen (anima, mens, spiritus, cor)?

[...] concede nobis, ut sit in cordibus nostris simplex affectus, patientia fortis, religio munda et immaculata, obedientia placita, pax perpetua, mens pura, conscientia sancta, compunctio spirtitualis, virtus animae, vita immaculata, consummatio irreprehensibilis, ut viriliter currentes, tuum mereamur regnum feliciter introire. Amen. ${ }^{17}$

Wenn das religiöse Subjekt in diesem Sinn innerhalb und außerhalb der traditionellen Hierarchie der Seelenkräfte konzipiert ist, kann das Nebeneinander auch Spannungen produzieren. ${ }^{18}$ Weil darüber hinaus in der christlichen Tradition religiöse und ästhetische Praxis in komplexen Gemengelagen immer schon miteinander vermittelt sind, ${ }^{19}$ können sich ästhetische delectatio und spirituelle aedificatio auch zur Konkurrenz werden, mit heiklen Folgen für den Wahrheitsstatus.

Während einerseits die innerbiblische, vor allem neutestamentlich verankerte und frühchristliche Geschichte des Erbauungsbegriffs gut erschlossen

16 "So verbindet sich die pastoraltheolog. Kategorie der Erbauung inhaltlich mit der Interpretation der christl. Existenz als eines paradoxen [...] Ineinanders von Leben u. Sterben. Erbauung tritt gewissermaßen zwischen Ermahnung $u$. Trost: Daß es beides - Leben, als ob man stürbe (Ermahnung) u. im Sterben [...] das Leben erkennen (Trost) - als geistl. Wirklichkeit in der irdischen zur Geltung zu bringen $u$. einzuüben, d. h. erfahrbar zu machen gilt, ist das Grundmotiv der Erbauung, das historisch entfaltet wird.« Mennecke-Haustein [Anm. 1], S. 234.

17 Gertrude d'Helfta: Euvres spirituelles [Anm. 4], II,108-113. Dass dieser zu erbauende affectus simplex ein Interpretationsproblem markiert, belegt der breit paraphrasierende Übersetzungsversuch des Begriffs durch Ringler [Anm. 4], S. 73: ses sei in unseren Herzen eine schlichte Gemütsbewegung ohne jeden Nebensinn`.

18 Zum vieldeutigen Terminus mens vor dem Hintergrund augustinischer Anthropologie und zu den angedeuteten Spannungen vgl. Susanne Köbele: Bonaventura. `Itinerarium mentis in deum (1259), in: Cornelia Herberichs u. Christian Kiening (Hgg.): Literarische Performativität. Lektüren vormoderner Texte, Zürich 2008 (Medienwandel - Medienwechsel - Medienwissen 3), S. 156-178, hier S. 171.

19 Zuletzt Peter Strohschneider (Hg): Literarische und religiöse Kommunikation im Mittelalter und Früher Neuzeit. DFG-Symposion 2006, Berlin u. New York 2009; Susanne Köbele u. Bruno Quast (Hgg.): Literarische Säkularisierung im Mittelalter, Berlin 2014 (Literatur-Theorie-Geschichte 4). 
ist, $^{20}$ anderseits mit Solbach ${ }^{21}$ auch für die frühneuzeitliche Situation interdisziplinär eine neue Basis geschaffen worden ist, im Blick auf die medial vielgestaltige Wirkungsweise von `Erbauung`, ist für die mittelalterliche Situation noch vieles ungeklärt. Zwar hat die mediävistische Forschung, u. a. im Ausgang von Auerbachs berühmter `Sermo humilis`-Abhandlung, ${ }^{22}$ durchaus heterogene Erbauungskonzepte beobachtet, im engen Kontakt zur Kunstgeschichte und hagiographischen Forschung, doch wurde für das Mittelalter >Erbauung`nur partiell in gattungsbezogenen Spezialuntersuchungen (besonders für die spätantike Bibelepik, die Legende, die Consolatio-Literatur ${ }^{23}$ ) differenzierter beschrieben. ${ }^{24}$ Erst wenn Erbauung sich aus Gattungsfragen löst, »lassen sich ihre Geschichte und ihre Metamorphosen bis in die Gegenwart verstehen«:

»Das Phänomen der Erbauung ist den Kulturwissenschaften seit langem wohl bekannt: Erste grundlegende Arbeiten zur Deutung der Erbauung wurden von Theologen und Religionswissenschaftlern vorgelegt, und ein überwältigender Teil der Forschung auf diesem Gebiet widmet sich der Untersuchung des protestantischen Erbauungsbuches im engeren Sinn. Doch hier macht sich eine Entwicklung bemerkbar, die sich auch außerhalb der germanistischen Forschung beobachten läßt und sich zudem in den Fachlexika spiegelt: Durch eine Verengung der Fragestellung wird die Sache und der Begriff der Erbauung zunehmend auf die Gattung der Erbauungsliteratur im strengen Sinn begrenzt. « ${ }^{25}$

20 Vgl. u. a. Philipp Vielhauer: Oikodome. Das Bild vom Bau in der christlichen Literatur vom Neuen Testament bis Clemens Alexandrinus, in: ders.: Aufsätze zum Neuen Testament, hg. v. Günter Klein, Bd. 2, München 1979, S. 1-168.

21 Vgl. Andreas Solbach (Hg.): Aedificatio. Erbauung im interkulturellen Kontext in der Frühen Neuzeit, Berlin 2005.

22 Vgl. Erich Auerbach: Sermo humilis, in: ders. (Hg.): Literatursprache und Publikum in der lateinischen Spätantike und im Mittelalter, Bern 1958, S. 25-53.

23 Vgl. Peter von Moos: Consolatio. Studien zur mittelalterlichen Trostliteratur über den Tod und zum Problem der christlichen Trauer, 4 Bde., München 1971/1972 (Münstersche Mittelalterschriften III/1-4).

24 Problemöffnend für die christliche `Erbauungs`-Ästhetik zwischen Auslegung (Allegorese, Exegese) und poetischer delectatio in der christlichen Spätantike waren die Überlegungen von Reinhart Herzog: Die Bibelepik der lateinischen Spätantike. Formgeschichte einer erbaulichen Gattung, München 1975 (Theorie und Geschichte der Literatur und der schönen Künste. Texte und Abhandlungen 37); außerdem ders. [Anm. 15]. Mit Bezug auf Legendenprologe: Rolf Schulmeister: Aedificatio und Imitatio. Studien zur intentionalen Poetik der Legende und Kunstlegende, Hamburg 1971. Zu Gebäudeallegorien im Spannungsfeld von Narration und Ekphrasis (u. a. Prudentius, Alanus, Jüngerer Titurel) vgl. Katharina Mertens Fleury: Zeigen und Bezeichnen. Zugänge zu allegorischem Erzählen im Mittelalter, Würzburg 2014 (Philologie der Kultur 9).

25 Solbach [Anm. 21], beide Zitate im Vorwort, S. IX. 
`Erbauung〈, soviel lässt sich in einer Zwischenbilanz festhalten, ist seit ihren christlichen Anfängen eine zugleich theologische, frömmigkeitspraktische und wirkungsästhetische (funktionale) Kategorie, die im Kern auf eine von Gott und Christus ausgehende, von den Propheten und Aposteln und den Christen untereinander zu befördernde Konsolidierung des Glaubens zielt und, weil der Akt des Glaubens auf je verschiedene (voluntative, imaginative, intellektuelle) Seelenkräfte beziehbar ist, als Vermittlungspraxis unterschiedliche, historisch und kontextabhängig variable Wirkungsabsichten einschließt.

Eine systematisch und historisch umfassende Phänomen- und Begriffsgeschichte von Erbauung im Mittelalter ist nach wie vor Desiderat. ${ }^{26}$ Wer sich dieser Aufgabe nähert, muss anachronistischen Begriffsverengungen widerstehen. Im Rückgriff auf populäre Konzepte des 18. und 19. Jahrhunderts, die Erbauung als fromme Gemütserhebung, Religiosität als gottseliges Gefühl isolieren, wird das religiös-ästhetische Spannungspotential von >Erbauung` im Mittelalter schnell übersehen oder unterschätzt. Hans-Henrik Krummacher ${ }^{27}$ überspringt in seinem historischen Abriss bezeichnenderweise das Mittelalter und schreitet von Augustinus gleich zum Pietismus weiter. Zur Abwertung, Schematisierung, Sentimentalisierung von Erbauung in den Erweckungsbewegungen des 19. Jahrhunderts, zur Tendenz, »literarische Erbauung religiös u. ästhetisch als kitschig-klischeehaftes u. eskapistisches Angebot religiöser Sinngebung zu diffamieren « ${ }^{28}$, ist es dann nur noch ein kleiner Schritt.

Im Unterschied zu erst frühneuzeitlich-pietistischen Festlegungen auf Innerlichkeit, religiöse Empfindsamkeit und diskursive Schlichtheit scheint im Mittelalter >Erbauung e eine sehr umfassende affektive, intellektuelle, moralische und ästhetische instructio, die sich nicht von selbst versteht, sondern je neu eine Balance herstellen muss und damit - in binnenreligiöser Perspektive Fehleinstellungen, Heilsrisiken, Übertreibungen ausgesetzt ist: der Versuchung selbstsicherer Heilszuversicht, selbstgenügsamer Vergnüglichkeit oder drittens

26 Für lat. aedificatio gibt es auch mittelhochdeutsch ein gleitend synonymisches Feld (trost, gedinge, bezzerunge, sterken, lere, etc.). Luther übersetzt aedificatio im Zuge einer religiösen Ethisierung des ursprünglich kultisch, kerygmatisch und ekklesiologisch geprägten Begriff häufig mit `Besserung`; dazu Vielhauer [Anm. 20], S. 95, der am Schluß seiner instruktiven, bis zur Spätantike reichende oikodome Begriffsgeschichte das Mittelalter überspringt, mit dem Hinweis auf noch zu erforschende allegorisierende Umdeutungen von Erbauung im Mittelalter (S. 162 f.). Für eine Rekonstruktion der historischen Semantik der Begriffe müssten die unterschiedlichen. Erbauungsbegriffe des Mittelalters einerseits, solche der Mediävisten anderseits kritisch auf den Punkt gebracht und miteinander abgeglichen werden. Diesen Versuch wird eine von Claudio Notz (Zürich) und mir geplante interdisziplinäre Tagung unternehmen.

27 Vgl. Hans-Henrik Krummacher: [Art.] Erbauung, in: HistWbPhil, Bd. 2, 1972, Sp. 601-604. 28 Mennecke-Haustein [Anm. 1], S. 238. 
allzu subtiler, selbstreferentiell geschlossener Spekulation, weswegen schon bei Paulus die Aussicht auf `Erbauung` (aedificatio, mit den Aspekten confirmatio, exhortatio, consolatio) zugleich mit diversen >Versuchungen` (temptationes) ihrer inneren oder äußeren Zerstörung konfrontiert ist (vgl. 2 Th 3,2-5).

Vor diesem Hintergrund wäre der zumindest implizite Gegenbegriff zu >Erbauung، nicht einfach nur Glaubensschwächung, nicht nur der Abbau von demütiger Glaubensgewissheit, sondern im Gegenteil auch deren unkontrollierte Übertreibung hin zum allzu Sublimen und Subtilen. Um nur den Punkt demütiger Heilszuversicht herauszugreifen: In der sich fortwährend reprozierenden Tendenz zur hochmütigen Überbietung der Demut liegt eine heikle Denkfalle, ja, das pragmatische und moralische Dilemma der christlichen vita religiosa schlechthin. Max Weber nennt dieses Dilemma das >Doppelgesichtı religiöser Askese. Kaum jemand hat die Paradoxie, dass jede Form der Weltabwendung im Ausschließen von Welt notwendig neue Welt produziert, besser auf den Punkt gebracht als er. ${ }^{29}$ Die erbauliche Instruktion, auf Erlösung hoffen, aber nicht mit ihr rechnen zu dürfen, hilft aus diesem Dilemma nur bedingt heraus. Die christliche Spannung von Demut und gewusster Exklusivität (Erwähltheit) bleibt quer durchs Mittelalter eine ziemlich umfassende Aporie, mit erheblichen theologischen, handlungspraktischen und, wie ich meine, auch poetologischen Folgen. Warum löst sie sich nicht einfach auf als eine Frage der rechten Proportion? Man könnte ja einwenden, eine sehr praktikable Option, das rechte Maß des `Erbaulichen $\mathrm{zu}$ finden, liege im Zählen und Messen, bewährten Disziplinierungsmitteln religiöser Vervollkommnung, wie die geradezu obsessive Unterteilung in `Stufen` oder `Grade، spiritueller Vollkommenheiten in der bernhardisch-franziskanischen Mystik des 12. und 13. Jahrhunderts belegt, ${ }^{30}$ zumal sich die Denkfigur gradueller Vermittlung (`Stufung`) für die gesuchte Mitte zwischen $\mathrm{zu}$ viel und $\mathrm{zu}$ wenig `Erbauung`in eben diese Bildvorstellung aufs Beste fügt?

So ist in dem breit überlieferten >Buch der Minne` (auch: >Rede von den 15 Graden $),{ }^{31}$ das im späteren 13. Jahrhundert im literarhistorischen Umfeld des >Rheinischen Marienlobs` und Bruns von Schonebeck Hohelied-Dichtung Nonnen und Beginen in der Gottesliebe unterweisen will, das Erbauungs-Thema die >Einwohnung`Gottes in der zu serbauenden` Seele - mit dem Aufstieg in

29 Vgl. Max Weber: Zwischenbetrachtung: Theorie der Stufen und Richtungen religiöser Weltablehnung (zuerst 1915), in: ders.: Gesammelte Aufsätze zur Religionssoziologie, Bd. I: Die Wirtschaftsethik der Weltreligionen, hg. v. Marianne Weber, 9. Aufl., Tübingen 1988 (UTB 1488), S. 536-573, hier S. 540.

30 Beispiele versammelt in reicher Fülle Ruh [Anm. 6].

31 Vgl. Dat Boec der Minnen (Die Rede von den XV Graden), hg. v. Johanna Marie WilleumierSchalij, Leiden 1946. Zum bernhardisch-viktorinischen Kontext Ruh [Anm. 6], S. 233-244. 
fünfzehn >Graden` der Liebe textkonstitutiv dadurch verbunden, dass Gott in verschiedenen Erscheinungsweisen und allegorischen Rollen in der Seele wohnt: als Gast, Pilger, Kaufmann, Hausherr, Arzt, etc., zuletzt als König, Bruder und Bräutigam, mit dem Ziel des räumlich exklusiven seligen Schlafs von Braut und Bräutigam. Nur: Hier wie generell im christlichen Entwurf von Heilsgeschichte bleibt das Risiko zu scheitern, am Anfang des Weges so groß wie an seinem Ende, anders gesagt: Es bleibt auch in traditionellen Stufenmodellen, die den spirituellen Fortschritt systematisch an ausdifferenzierte Hierarchien binden, für Anfänger und Fortschreitende bis zur letzten Sekunde der hora mortis immer dasselbe Risiko. Unternimmt man, statt Stufen und Grade auszumessen auf dem Weg nach oben, gleich einen Ebenensprung, ergeben sich andere Unsicherheiten. Das >Buch der Minne` entscheidet sich dafür, beide Modelle (regulierte Kontinuität und spontane Diskontinuität) zu verbinden, indem erst die beiden letzten der insgesamt 15 Einwohnungen der in Gott erbauten Seele, die sich auf die kontemplative Gotteserkenntnis beziehen, die Kategorie des Sprungs in Anschlag bringen: Die kontemplierende Seele springe einen großen und seligen Sprung in den Baumgarten oder Weinkeller (bzw. in der Parallelüberlieferung: die Gewürzkammer oder Schlafkammer) des göttlichen Bräutigams. ${ }^{32}$ Andere Bildmodelle, die die immanente Grenze einübbarer Erbauung markieren und zugleich überschreiten, wären systematisch zu eruieren. Wie kommen der absolute Unmittelbarkeitsanspruch (die Totalität >reiner Minne) und der relative Anspruch gestufter Gottesnähe in der religiösen Kultur des Spätmittelalters serbaulich` zur Deckung? Erbauung als geistliche `Erhebung impliziert eine aufsteigende Dynamik, ein Aufbauen und Aufrichten auch im übertragenen Sinn von Trösten - aber wenn der Boden (fundamentum) des erbauten Hauses zum Abgrund (abyssus) wird?

Statt die hier skizzierten Spannungen in einem pauschalen Funktionsbereich >Erbauung، aufgehen zu lassen oder aber als Einzelaspekte auf separate Gattungen zu verteilen, sei anhand exemplarischer Textvergleiche der Versuch gemacht, sie synchron wahrzunehmen, in der Hoffnung, dem internen Konfliktpotential des historisch so voraussetzungs- wie folgenreichen Begriffs der `Erbauung ‘ür das späte Mittelalter auf die Spur zu kommen.

32 Vgl. Dat Boec der Minnen: III,21-IV,3. Vgl. dazu Ruh [Anm. 6], S. 237, mit Hinweis auf die Parallelüberlieferung. 


\section{Erbauen, Versinken}

Wenn, wie Burkhard Hasebrink im nachfolgenden Beitrag schlagend herausarbeitet, in Meister Eckharts radikaler Transformation religiöser Lebensformen das Mittelalter so christlich wird, „dass es die Grenzen dieser Religion gleichsam von innen überwindet«, scheint eben diese institutionell heikle »Selbstüberschreitung der Religion«, die »mitten im Zentrum der christlichen Religion deren Versprechen auf Operationalisierbarkeit von Vollkommenheit und Heiligkeit die epistemologische Basis entzieht ${ }^{33}$, über Eckharts unbestreitbaren Neuansatz hinaus auch generell als Grundparadoxie religiöser Kommunikation fassbar. Dass die Einsicht in die grundsätzliche Unabschließbarkeit religiöser Symbolisierungsprozesse gerade die Mystik, indem sie auf einen »reinen Sinn der Religion « ${ }^{34}$ ziele, spezifisch anschlussfähig für die Moderne mache, hat schon Ernst Cassirer formuliert freilich offen fortschrittsteleologisch: Die Mystik gilt ihm als Telos eines religiösen Gesamtprozesses, der über die Leibniz'sche Eckhart-Rezeption und Schleiermachers kontemplative Hermeneutik in das ästhetische Bewußtsein der Neuzeit führe. Achtet man mit einem an Eckharts emphatischer Transformation des Armutsgebots geschärften Blick auf diese Hintergrundspannung auch in weniger zugespitzten Fällen, tritt sie dort, wie mir scheint, überhaupt erst zu Tage, umso deutlicher, je programmatischer auf der Textoberfläche eben jene serbauliche` Operationalisierbarkeit religiöser Vollkommenheit behauptet und stabilisiert wird. $\mathrm{Zu}$ denken gibt dabei, dass viele dieser sich performativ selbst widerlegenden Texte auf der Metaebene, im Titel oder in ihren eigenen analytischen Verfahrensbegriffen, genau das

33 Burkhard Hasebrink: Selbstüberschreitung der Religion in der Mystik. >Höchste Armut bei Meister Eckhart, in: PBB 137 [2015], S. 446-460, hier S. 460.

34 Vgl. Ernst Cassirer: Philosophie der symbolischen Formen. Zweiter Teil: Das mythische Denken, Darmstadt 1994 (zuerst 1925), hier S. 298 f. (mit Bezug auf Eckhart, zum »Grundgedanke[n] einer Polarität, die sich in reine Korrelation aufzulösen strebt und die doch nichtsdestoweniger als Polarität erhalten werden muß«). »Wir stehen damit vor einer Grundanschauung, deren volle Entwicklung und Ausbildung über die Grenzen des religiösen Bereichs hinausführt. Erst in der Geschichte des modernen philosophischen Idealismus hat die neue Ansicht des 'Symbols`, die in der Mystik durchbricht, ihre volle gedankliche Ausprägung erfahren« (ebd., S. 308). Die dem religiösen Gesamtprozeß immanente Spannung zwischen Evidenz und Auslegung komme, so Cassirer, nie zur Ruhe: „Könnte an Stelle dieses In- und Gegeneinander jemals das reine und völlige Gleichgewicht treten, so wäre damit auch die innere Spannung der Religion aufgehoben, auf der ihre Bedeutung als `symbolische Form « beruht« (S. 311). Cassirer sieht in den letzten Sätzen seiner >Philosophie der symbolischen Formen` das religiöse Bewusstsein in das ästhetische überführt: »Das ästhetische Bewußtsein erst läßt dieses Problem wahrhaft hinter sich« - signifikanterweise über die Kategorie der Kontemplation (»[i]ndem es sich von Anfang an der reinen Betrachtung überläßt«, [ebd.]). 
sein wollen (nämlich: exercitia spiritualia, itinerarium mentis in deum, Herzkloster $^{35}$, speculatio), worüber sie auf der Objektebene sprechen: Als methodische Gebets-Einübung sind sie zugleich auch Gebets-Serie, als Weganleitung zugleich Weg, als Erbauung zugleich selbst das erbaute Gebäude. Welche Auswirkungen haben solche Kongruenzen auf die Textpoetik? Diese Frage könnte ein aussichtsreicheres Instrument sein, Differenzierungen innerhalb der bernhardisch-franziskanisch geprägten Literatur der Zeit zu beschreiben, als der oft bemühte Kontrast von literarischer Konvention und spiritueller $>$ Erfahrung ${ }^{36}$.

Wenn die Letzten, arm an Geld oder Geist, vor Gott die Ersten und reich sein werden (Mt 19,30), wenn also Armut reich macht und glücklich (Mt 5,3), dann bedeutet diese kategoriale Inversion von Arm und Reich eine unendliche Verführbarkeit: reich vor Gott oder, wenigstens ein bisschen, schon in der Augen der Welt? Demgegenüber wirkt die unabschließbare Doppelanstrengung Eckharts, das NichtWollen nicht wollen zu sollen, in der Tat gesteigert (১radikalı) paradox. Aber ist sie das wirklich? Ist Eckharts emphatische Raum-Zeit-Abstraktion von Armut unabschließbarer paradox als jene urchristlich-programmatischen Arm-Reich-Umwertungen der Bergpredigt? Für die logische Operation Paradoxie lässt sich schwerlich ein Komparativ ansetzen. Daher würde ich zur Klärung der Ebene der Vergleichbarkeit folgendes vorschlagen: Beide Male werden auf derselben Metaebene mit

$35 \mathrm{Zu}$ dieser seit dem 12. Jahrhundert populären Texttradition vgl. im Überblick Gerhard Bauer: [Art.] Herzklosterallegorien, in: ${ }^{2}$ VL, Bd. 3, 1981, Sp. 1153-1167. Ruh [Anm. 5 u. 6], hat den entscheidenden Vorstoß unternommen, Gertrud von der »katholisch->barocken` Patina« (Ruh, [Anm. 6], S. 336), die ihr anhaftete, zu befreien, u. a. mit dem Hinweis auf die zentrale Prägung ihrer Texte durch Liturgie und Bibelsprache; dazu auch bereits Jacques Hourlier u. Albert Schmitt [Anm. 4], S. 7-51, bes. S. 32-35.

36 Vgl. Maren Ankermannn: Gertrud die Große von Helfta. Eine Studie zum Spannungsverhältnis von religiöser Erfahrung und literarischer Gestaltung in mystischen Werken, Göppingen 1997; Sabine B. Spitzlei: Erfahrungsraum Herz. Zur Mystik des Zisterzienserinnenklosters Helfta im 13. Jahrhundert, Stuttgart-Bad Cannstatt 1991; Sabine B. Marquardt-Spitzlei: O Gott meines Herzens - Das Herz als Erfahrungsraum Gottes in den `Exercitia spiritualia`, in: Siegfried Ringler (Hg.): Aufbruch zu neuer Gottesrede. Die Mystik der Gertrud von Helfta, Ostfildern 2008, S. 4660. Gertruds Werke seien in die biblisch-liturgische Latinität und geistliche Liebessprache des 12. Jahrhunderts eingebunden, »aber nie als fertige Münze, sondern als erfahrene Aussage«, so Ruh [Anm. 6, S. 335], der ihre Schriften "zu den schönsten, die Frauen verfaßt haben« (Ruh [Anm. 5], S. 19) zählt. Den ihr vom 17. Jahrhundert gegebenen Beinamen >die Große` verweigert er Gertrud als einer »Mystikerin der Innigkeit«: »Ich verwende ihn nicht, da er mir für eine Klosterfrau unpassend erscheint (Ruh [Anm. 6], S. 300). Damit sind, mitten im so verdienstvollen wie erfolgreichen Versuch, Gertrud aus der Vereinnahmung durch allzu süße Herz-JesuVerehrung zu befreien, genau die Spannungen im Erbauungskonzept, denen ich hier nachzugehen versuche, auf der Metaebene überraschend wieder da: schön, innig, schlicht, aber nicht (oder nur unangemessenerweise) groß. 
derselben Paradoxieanfälligkeit die epistemischen Möglichkeiten des Menschen verhandelt: biblisch über die kategoriale, aber erst endzeitlich akute Differenz von Mensch und Gott, bei Eckhart über eine präsentische Aktualisierung der Aufhebung dieser Mensch-Gott-Differenz, weswegen in dieser entzeitlichten Perspektive (nunc, nicht tunc) mit der Verlaufsdimension nicht nur Nichtwissen, sondern die kategoriale Differenz von Wissen und Nichtwissen überhaupt zurückgelassen werden soll und Armut als objektlose Hingabe nicht um des Menschen willen, nicht einmal um Gottes willen, sondern rein um der Hingabe als solcher willen gilt. Statt die zu verkündigende Wahrheit in ein heilszeitliches Früher oder Später auseinanderzulegen, beschwören Eckharts Predigten eine umfassende Differenzlosigkeit (einunge) und emphatische Kontemporalität (nû, alzemâle). Natürlich ist das eine andere `Radikalität`, aber doch hier wie dort dieselbe Paradoxieanfälligkeit und operationale Unabschließbarkeit. Eckharts Wollen des Nichtwollens kann schwer erfolgreich an ein Ende kommen. Aber ein vergleichbarer immanenter Widerstand liegt auch der biblischen Inversionsfigur zugrunde. Eckharts kategoriale Überbietung geistiger Armut und die biblische kategoriale Umwertung von Arm und Reich hängen also, darauf will ich hier nur hinaus, auf intrikate Weise zusammen. Denn auch wenn das jenseits von Intention vorgestellte Nicht-Wollen von Wissenwollen der Eckhart'schen Armutspredigt anderes Nichtwissen (wo es noch ein Habenwollen ist) kategorial überbieten will (১willı), macht dieses Konzept von Armut sich verwechselbar: mit eben den Simplen unter den simplices, die nach Mt 5,3 bis zum Schluss darauf hoffen können (wenn auch nicht damit rechnen dürfen), vor Gott für weise zu gelten. Und deswegen hilft es Eckhart auch vor den Kölner Zensoren nichts, wenn er zur Verteidigung seines brisanten Konzepts des Leer- und Einfachwerdens ausgerechnet die glücklichen Armen aus Mt 5,3 anführt. ${ }^{37}$

Häresien markieren in der Geschichte von Glaubensgemeinschaften schwerwiegende Krisen. Sie demonstrieren, dass, historisch gesprochen, die Frage nach der Christlichkeit des Mittelalters einerseits die strikte Alternative `christlich snichtchristlich< voraussetzt: den kategorialen Gegensatz >christiani/non christia$n i<$, der sich selbst asymmetrisch versteht (`Christen-Heiden`) und in der dogmatischen Binnenperspektive wiederkehrt als Gegensatz >orthodox-heterodox`. Hier gibt es nur Inklusion oder Exklusion, und wie kategorisch das christliche Mittelalter diese Grenze versteht, zeigt das Konzept der ewigen Hölle. Anderseits und

37 Vgl. Meister Eckhart: Die deutschen und lateinischen Werke, hg. im Auftrag der Deutschen Forschungsgemeinschaft [DW/LW], Stuttgart 1936 ff. Processus contra mag. Echardum n. 48 (Proc. Col. I, n, 97), LW V, S. 283,11-284,2: Sic oculus carens colore colorem accipit, cognoscit et delectatur colore. Paries autem habens colorem nec se scit habere colorem nec ipso delectatur. Propter quod Matth. 5 pauperes dicuntur beati. Dazu Hasebrink [Anm. 33], S. 455, Anm. 38. 
zugleich wird im selben Diskurs mit einer offenen Skala von >mehr oder weniger christlicher« Christlichkeit argumentiert. Christlichkeit ist also steigerbar, einübbar, widerrufbar. Häresieverdächtige Aussagen können >dem Wortlaut nach nicht-christlich >klingen`, obwohl sie sich der >Intention` oder dem `Sinn « nach durchaus als christlich (d. h. orthodox) verstehen. Es bleibt also auch und gerade dort, wo die Frage >Wie christlich ist das Mittelalter? « rechtsrelevant wird, ein nicht geringer Spielraum der Auslegung, zumal für volkssprachliche Aussagen, die, um überhaupt prozessfähig zu werden, ins Lateinische übertragen wurden.

Die Rede von der >Christlichkeit` des Mittelalters lässt, parallel zum strikten Gegensatz von christlich-nichtchristlich, graduelle Abstufungen und bereichsspezifische Differenzierungen $\mathrm{zu}$, erzwingt sie geradezu. Genau daraus, aus dieser systematisch und historisch heterogenen Lage, resultiert das eminente Konfliktpotential des christlichen Mittelalters. Die Frage >Wie christlich ist das Mittelalter?^ legt aspekthaft Verschiedenes nahe, nämlich die Fragen: >Wie rechtgläubig (im Sinn der Institution)<, >wie religiös (als innere Haltung, Glaubenspraxis, Symbolisierungsprozess)<, >wie geistlich (als nicht-säkulare Sicht)< oder >wie klerikal (als Standesethos) ist das Mittelalter?^ Die einschlägigen Gegensatzkonstellationen (orthodox-heterodox, geistlich-weltlich, sakral-säkular, klerikal-laikal) überschneiden sich uneindeutig und führen in ganz verschiedene Gebiete. Dennoch sind sie verbunden durch die übergreifende Frage: Wie geht die >christliche Leitkultur des Mittelalters um mit dem Nichtchristlichen außerhalb und innerhalb ihrer selbst?

Sind nun also die Verführbarkeiten (nach innen) bzw. Verwechslungsrisiken (nach außen) für die geistig Armen aus der Bergpredigt kleiner (oder nur weniger akut?) als für die geistig Armen im Sinne Eckharts?

Methodische Heilssuche, so möchte ich die Überlegungen von Hasebrink aufnehmen und weiterführen, ist im christlichen Mittelalter generell auf dem Prüfstand, auch wenn ihre Umdeutung durch Eckharts verabsolutierte Gegenwartsperspektive sie zweifellos am kompromisslosesten aus den Angeln hebt. Zwar bleibt das erhebliche Spannungspotential, das in der literarisch produktiven Vorstellung der Einübbarkeit (exercitatio) und gestuften Erbauung (aedificatio) von Heilszuversicht liegt, in den einschlägigen Texten häufig verborgen. Doch zeigt sich, wie eingangs angedeutet, gerade in den forciertesten Verlaufsmodellen von Aufstieg und gestuftem Fortschritt die inhärente Problematik religiöser Vollkommenheitskonzepte, und zwar dann, wenn man darauf achtet, 
wie Verlaufsprozesse mit konkurrierenden Zeitlogiken konfrontiert werden, mit Synchronisierungsmodellen, ${ }^{38}$ die Umschlageffekte bewirken und unauflösliche Widersprüche.

Natürlich ist evident, dass solche Paradoxierungen der Zeitverhältnisse die Mystiker besonders >radikale` Transgressionen der religiösen Lebensform erfinden lassen: Wenn der grunt [...] dâ alliu guot ûf gebûwet möhten werden ${ }^{39}$, kein fester Boden, sondern ein Abgrund ist, in dem der Seelengrund und Gottes Grund einander nicht nur ähnlich werden, sondern eins, je tiefer, um so geistig ärmer, ${ }^{40}$ oder wenn die räumliche Distanz zur Welt sich als (innere, habituelle) >Abgeschiedenheit` völlig löst vom realen exklusiven Raum des Klosters ${ }^{41}$, dann versteht man, warum das konventionelle Modell `Erbauung`gerade bei Eckhart auffällig zurücktritt bzw. transformiert wird, insbesondere in seinen volkssprachlichen Predigten, die den Spielraum größerer terminologischer Offenheit von mhd. grunt gegenüber der ausdifferenzierten Fachsprachlichkeit des Lateinischen (fundamentum, basis, profundum, abyssus, abditum, ratio) spezifisch nutzen. Signifikant ist in diesem Zusammenhang Eckharts berühmte Intravit in templum-Predigt (Q 1), die nicht das Aufbauen, sondern das Leerwerden des Tempels (= der Seele) als zeitlos-neues ısüßes` Versinken der Seele mit Gott beschreibt, in unendlicher Dynamik des Zunichtewerdens im Nichts durch Gottes noch unter dem Nichts der Seele stehendes Nichts. Was bei Eckhart der

38 Vgl. Christian Kiening [u. a.] (Hgg.): Wiederkehr und Verheißung. Dynamiken der Medialität in der Zeitlichkeit, Zürich 2011 (MW 16); außerdem Susanne Köbele u. Coralie Rippl (Hgg.): Gleichzeitigkeit. Narrative Synchronisierungsmodelle in der Literatur des Mittelalters und der Frühen Neuzeit, Würzburg (Philologie der Kultur), im Druck.

39 Meister Eckhart: Die deutschen und lateinischen Werke, Abt. I: Die deutschen Werke. Deutsche Predigten und Traktate, hg. und übers. v. Josef Quint, München 1963, S. $297,9$.

40 Meister Eckhart [Anm. 41]: Von dem edlen Menschen, DW V, S. 117,11 ff.: Die gottgeeinte Seele schöpfe alles, was sie ist, von dem grunde gotes und enweiz von wizzenne niht noch von minne noch von nihte alzemâle; zugleich hält Eckhart für den unmittelbaren Gottesbezug an der Konvention Gebäude/Erbauung fest (die Wand sei etwas anderes als das Fundament, auf dem die Wand gebaut ist); vgl. außerdem die `Erfurter Reden`, ebd.: Kap. 19, DW V, S. 262,4 f.: Wer sich als luter niht erkenne, als reines, leeres Nichts, der werde umso tiefer in Gott versetzt; ebd.: Kap. 23, DW V, S. 300,1: Wer arm von geiste, könne das Armwerden durch Spenden für den Bau von Klausen und Klöstern sein lassen.

41 Vgl. Burkhard Hasebrink: Die Anthropologie der Abgeschiedenheit. Urbane Ortlosigkeit bei Meister Eckhart, in: Freimut Löser u. Dietmar Mieth (Hgg.): Meister Eckhart im Original, Stuttgart 2013 (Meister-Eckhart-Jahrbuch 7), S. 139-154. Zu den Kontexten der berühmten Formel ınichts haben - nichts wollen - nichts wissen` vgl. Freimut Löser: Der niht enwil und niht enweiz und niht enhât. Drei übersehene Texte Meister Eckharts zur Armutslehre, in: Claudia Brinker [u. a.] (Hgg.): Contemplata aliis tradere. Studien zum Verhältnis von Literatur und Spiritualität. Festschrift für Alois M. Haas zum 60. Geburtstag, Bern [u. a.] 1995, S. 391-440. 
Prozess einer umfassenden Abstraktion vom Hier und Jetzt durch die Vernunft ist (daz si abescheidet von hie und von nû, 48,2 f., in Q 70), bei der es nicht darauf ankommt, ob man sich im Kloster von der Welt separiert oder an einem beliebigen anderen Ort, wird als Abstraktionsleistung auch andernorts beobachtbar, etwa in auffälligen Metaphorisierungen ${ }^{42}$, die mit ihrer Spaltung in eine literale und übertragene Klosterexistenz Eckharts Verabsolutierung (oder Habitualisierung?) der Abgeschiedenheit zumindest vergleichbar machen: indem man im (veritablen) Kloster zugleich als >Kloster` der Minne erbaut werden soll; indem man im Vorwegnehmen des (realen) Todes zugleich der Welt sabsterben`soll.

Anders gesagt: Verbindet man die referentiell vielschichtige Spiritualisierung des Postulats >geistiger Armut ‘ in der Mystik mit der genuin biblischen Denkfigur der Inversion von Arm und Reich, schärft sich von Eckharts radikaler "Suspendierung grundlegender Repräsentationsmuster der vita religiosa ${ }^{43}$ aus der Blick für andere, weniger spektakuläre Fälle, die sich am selben Problem abarbeiten und die Spannungen, indem sie sie verbergen, nicht ausräumen. Wiederkehrende, dem Erbauungs-Konzept inhärente Bildkonkurrenzen von Grund und Abgrund, von Erbauen und Versinken, Erbauen und Bebauen ${ }^{44}$ weisen hier wie dort auf übergreifende Spannungen hin.

Gerade im 12. und 13. Jahrhundert finden sich in auffälliger Dichte Texte, die weniger die Vermittlung von Glaubensinhalten als vielmehr die Einübung von Glaubenshaltungen in den Mittelpunkt ihrer Texte stellen (üebunge/exercitium) und auf diese Weise Aufstiegs- und Einheitsmetaphysik kompromissbereit vermitteln. Sie präsentieren ein breites Spektrum von >Übungen`, in welcher Ausprägung auch immer (als exercitium speculationis, exercitium amoris oder contemplationis) ${ }^{45}$,

42 Der Ausdruck `Metaphorisierung i ist dabei nicht misszuverstehen. Gemeint sind, in Analogie $\mathrm{zu}$ `episch realisierten` Metaphern, gewissermaßen `spirituell realisierte Metaphern, die Eckhart auf den rekurrenten Begriff bzw. Vorgang des sich erbilden bringt (vgl. s. v. erbilden die Einträge im Wörterverzeichnis der Stuttgarter Eckhart-Ausgabe [Anm. 39]).

43 Hasebrink [Anm. 33], S. XXX [= Ms. S. 4].

44 In Eckharts Pr. 70 (Stuttgarter Eckhart-Ausgabe [Anm. 39]) heißt es am Ende: ১Die Vernunft als oberste Seelenkraft durchbreche alle Winkel der Gottheit und nehme den Sohn im Grund als Durchbruch in den göttlichen Grund (52,25). Sie breche ein in den göttlichen Grund (52,31), die Vernunft scheide alles ab und dringe in die Wurzel ein, aus der der Sohn ausquelle und der heilige Geist ausblühe.

45 Itinerarium mentis in Deum [Anm. 8], hier IV,3. Es handelt sich um einen Schlüsseltext für die Ambivalenzen eines nach innen verlagerten Stufenmodells religiöser Selbstvervollkommnung. Hier entwirft Bonaventura einen gestuften >Pilgerweg des Geistes in sieben Kapiteln, dessen Ziel - nach zwei Mal drei Stationen der Weltabwendung (extra nos), Selbstzuwendung (intra nos) und Selbsttranszendierung (supra nos) - auf der siebten Stufe die Verwandlung in Gott ist (transitus in deum). 
aber signalisieren zugleich die Grenze aller noch so subtil einzuübenden Kunst der Selbsttranszendierung. Einübbare Techniken religiöser Selbsttransformation und Heilssicherung (exercitia spiritualia) üben offenbar ihre unhintergehbare Entzogenheit zugleich mit ein, wodurch die Texte ihre eigenen performativen Dynamiken entfalten. exercitatio scheint in diesem Sinn ein Interferenzbegriff, der die Grenze zwischen repetitiver E i n ü b u n g und selbstwirksamen V o $11 \mathrm{z} \mathrm{u} \mathrm{g,} \mathrm{zwischen} \mathrm{Ak-}$ tivität und Passivität gerne überspielt.

Bei all diesen Spannungen scheint auch das sprachliche Medium - die sniedrige`, demütig-schlichte Volkssprache und das serhabene`, sublime und subtile Latein - eine Rolle zu spielen, sowohl für übergreifende Spannungen zwischen der diskursprägenden Schriftkultur der Kleriker und der laikalen Kriegergesellschaft, wie auch - und darauf richtet sich mein Interesse - für Spannungen in $\mathrm{n}$ e r h a $\mathrm{l} \mathrm{b}$ der christlichen Leitkultur.

\section{Disziplinierung und Überschreitung: sErbauung، in Gertruds von Helfta ১Exercitia spiritualia`}

Die Konstellation ist berühmt: Gegen Ende des 13. Jahrhunderts treffen Mechthild von Magdeburg, Mechthild von Hackeborn und, als jüngste der drei, Gertrud im Zisterzienserinnenkloster Helfta bei Eisleben aufeinander. Binnen weniger Jahrzehnte wird der Helftaer Konvent zu einem Zentrum volkssprachlich-lateinischer Visions- und Offenbarungsliteratur. Eine ganze Reihe gemeinschaftlich oder stellvertretend verfasster Texte entstehen, denen die Mystikforschung gerade in jüngerer Zeit verstärkte Aufmerksamkeit geschenkt hat. ${ }^{46}$ Von diesem Interesse

46 Vgl. im Überblick Kurt Ruh [Anm. 6], S. 296-337; zum Helftaer Textcorpus im Kontext der Zisterzienserinnen-Literatur vgl. Tanja Mattern: Literatur der Zisterzienserinnen. Edition und Untersuchung einer Wienhäuser Legendenhandschrift, Tübingen u. Basel 2011 (Bibliotheca Germanica 56), S. 341-387. Zum soziokulturellen Sonderstatus von Helfta vgl. Kaspar Elm: Frömmigkeit und Ordensleben in deutschen Frauenklöstern des 13. und 14. Jahrhunderts, in: Ons geestelijk Erf 66 (1992), S. 28-45. 
weitgehend ausgenommen blieben die Gertrud zugeschriebenen `Exercitia spiritualia $\iota^{47}$, ein Werk, das bis heute im Schatten des $>$ Legatus divinae pietatis steht. $^{48}$

Von den `Exercitia` besitzen wir keine handschriftliche Überlieferung, sondern einzig Druck-Überlieferung aus dem 16. Jahrhundert durch den Kölner Kartäuser Johannes Justus Lanspergius, der, nicht zuletzt über die Überlieferungssymbiose mit dem >Legatus`, auch die Zuschreibung an Gertrud von Helfta etabliert hat. ${ }^{49}$ Alle späteren Ausgaben (fast 50 Druckausgaben beider Werke im

47 Textausgaben [Anm. 4]. Kritisch zur Annahme, dass die seit dem Kölner Druck von 1536 unter dem Namen Gertruds laufenden `Exercitia spiritualia zu einem der von Gertrud verfassten Opera minora gehört haben könnten: Balázs J. Nemes: Die `Geistlichen Übungen`Gertruds von Helfta. Ein vergessenes Zeugnis mittelalterlicher Mystik, IASLonline [06.11.2004].

(URL: http://iasl.uni-muenchen.de/rezensio/liste/Nemes3980278867_1109.html [Aufrufdatum: 31.05.2015]). Für meine Zusammenhänge stelle ich Autorschaftsfragen zurück.

48 Von den insgesamt fünf Büchern des >Legatus` gehört nur das zweite, entstanden 1289, Gertrud; die übrigen Bücher, deutlich verschieden in Inhalt und Ton, sind wohl von einer Mitschwester aufgezeichnet worden. Vgl. zuletzt Almuth Märker u. Balázs J. Nemes: Hunc tercium conscripsi cum maximo labore occultandi. Schwester N von Helfta und ihre `Sonderausgabe 'Legatus divinae pietatis` Gertruds von Helfta in der Leipziger Handschrift Ms 827, in: PBB 137 (2015), S. 248-296; hier auch zusammenfassende Überlegungen zum Sonderstatus des `Eliteklosters` Helfta, zum einzigartigen klerikalen Netzwerk dieses Konvents, im Blick auf die z. T. hochgebildeten, überwiegend aus mitteldeutschem Adel stammenden Nonnen. Übergreifende Literatur: Gertrud Jaron Lewis: Das Gottes- und Menschenbild im Werk der mittelalterlichen Mystikerin Gertrud von Helfta, in: Geist und Leben 63/2 (1990), S. 53-69; Hugues Minguet: Théologie spirituelle de sainte Gertrude. Le Livre II du Héraut, in: Collectanea Cisterciensia 51 (1989), S. 147-177; 252-280; 317-328; Siegfried Ringler: Die Rezeption Gertruds von Helfta im Bereich süddeutscher Frauenklöster, in: Michael Bangert u. Hildegund Keul (Hgg.): Vor dir steht die leere Schale meiner Sehnsucht. Die Mystik der Frauen von Helfta, Leipzig 1998, S. 134-155. Im Überblick: Klaus Grubmüller: [Art.] Gertrud von Helfta, in: ${ }^{2}$ VL, Bd. 3, 1981, Sp. 7-10; Bd. 11, 2004, Sp. 520; Ulrich Köpf: [Art.] Gertrud (die Große) von Helfta, in: TRE, Bd. 12, 1984, S. 538-540.

49 Die `Geistlichen Übungen` werden in einem Kölner Druck aus dem Jahre 1536 im Anschluss an Gertruds >Legatus diviniae pietatis` überliefert. Der Herausgeber Lanspergius kündigt sie wie folgt an: "Adiiciuntur exercitia eiusdem nonnulla pia et rara in dei amorem vehementer inflammantia, quae librum claudunt. Hier wird behauptet, beide Texte hätten dieselbe Person zum Verfasser. Tatsächlich lesen wir in der in Paris 1578 verlegten, ebenso von Lanspergius verantworteten Einzelausgabe der `Exercitia<, sie würden, wie man glaubt (vt creditur), von Gertrud stammen. Das ist die schmale Basis, die es der Forschung ermöglicht hat, Gertrud von Helfta als Autorin der Übungen zu etablieren und den von Lansperg vorgelegten Text in das Helftaer Schrifttum des 13. Jahrhunderts einzureihen« (Nemes [Anm. 47], S. 1). Vgl. außerdem Ruh [Anm. 6], S. 319 zur Überlieferung der Druckausgaben. Zur Rolle von Lanspergius für die Textkonstitution Hourlier/Schmitt [Anm. 4], Introduction S. 7-51, hier S. 41-44. Lanspergius verhalf Gertrud zu immenser Wirkung in der ganzen katholischen Welt. Ihr >Legatus divinae pietatis` war im 16. und 17. Jahrhundert ein in viele Sprachen übersetzter Erfolg. Erwähnung 
16. und 17. Jahrhundert), inklusive der im Jahr 2001 von Siegfried Ringler auf der Basis der Sources Chrétiennes-Editionen erstellten `Exercitia`-Ausgabe [Anm. 4], gehen auf diesen Kölner Druck aus dem Jahr 1536 zurück. Auch wenn umfassende systematische Untersuchungen dazu fehlen, spricht derzeit alles dafür, die `Exercitia` zumindest im engsten Umfeld Gertruds und der von ihr entscheidend getragenen Helftaer Literaturproduktion anzusiedeln.

Grubmüller bezeichnet die >Exercitia< lapidar als »Erbauungsbuch, das in sieben Übungen zur geistlichen Vervollkommnung und zur fortschreitenden Vereinigung mit Gott führt « ${ }^{50}$. Ein Erbauungsbuch - in welchem Sinn? Und wie verhält Erbauung sich zur titelgebenden Übung? >Übung` ist als Kunst bzw. Technik religiöser Vervollkommnung im Zusammenhang zu sehen mit dem Bereich der sog. saszetischen` Literatur, die sich seit den Wüstenvätern entsprechend der griechischen Etymologie (askesis = Wettkampftraining) als systematisch regulierte Einübung in religiöse Vollkommenheit versteht. Nachmittelalterlich wird sie vor allem für die jesuitische Spiritualität prägend, die das Konzept geistlicher Übungen mit einem klaren Dreischritt formalisiert (sinnliche Vergegenwärtigung, Deutung und praktische Umsetzung des Heilsgeschehens: propositio, explicatio, applicatio $).^{51}$

Gertruds >Exercitia spiritualia`, so hat es Kurt Ruh formuliert,

»sind trotz übereinstimmendem Titel keine `Exerzitien` im Sinne des Ignatius von Loyola, wohl aber weisen sie auf sie hin. Der Terminus, seit der Karolingerzeit bekannt, aber zunächst selten verwendet, deckt sich am ehesten mit `Meditationen`, sodann, im Verlauf des 12. Jahrhunderts, immer mehr mit der Gebetspraxis. Methodischen Charakter hat diese noch nicht, aber die Konzentration auf bestimmte Themen in bestimmter Folge, verbunden mit praktischen Anweisungen, wie sie Gertrud in ihren `Exercitia` vorgenommen hat, ist ein bedeutender Schritt zu methodischen Gebets- und Meditationsübungen. « ${ }^{52}$

Dieser schwer zu bestimmende Status der exercitia interessiert mich im Folgenden. Vielleicht lässt er sich textanalytisch klären, vor dem Hintergrund der

verdient in diesem Zusammenhang eine Bearbeitung des `Legatus` aus dem 15. Jahrhundert unter dem Titel ein botte der götlichen miltekeit. Der unbekannte Verfasser modifizierte das Werk Gertruds durch Umstellungen und Kürzungen entsprechend dem theologischen Diskurs des 15. Jahrhunderts: Gertrud von Helfta: ein botte der götlichen miltekeit, hg. v. Otmar Wieland, Ottobeuren 1973 (Studien und Mitteilungen zur Geschichte des Benediktiner-Ordens und seiner Zweige. Ergänzungsbd. 22).

50 Grubmüller [Anm. 48], hier Sp. 9.

51 Vgl. Brückner [Anm. 1], S. 502 f.; außerdem Jean Leclercq [u. a.]: [Art.] Exercices spirituels, in: DAM, Bd. 4, 1961, Sp. 1902-1933.

52 Ruh [Anm. 6], S. 333. 
vorausgehenden Überlegungen zur inneren Ambivalenz von Erbauungsansprüchen, die die Medialisierung religiöser Lebensformen, indem sie sie unablässig beschwören und systematisch ausfalten, zugleich grundlegend hinterfragen.

Die `Exercitia spiritualia` vergegenwärtigen `feierlich` (celebrare spiritualiter, IV,1 f.) sieben Stationen des geistlichen Lebens, Stationen einer exemplarischen vita spiritualis im engeren Sinn des monastischen Lebens, aber auch schlechthin der religiösen Existenz, derer in wiederkehrenden Rhythmen an einem jeweils dafür bestimmten Tag gedacht werden soll. Gertruds sieben Stationen führen insgesamt über die Taufe (Übung I) und die conversio beim Klostereintritt (II) über die spezifischen, als ısüßer Liebesbund ` aufgefassten Rituale der Weihung (III) und der Profess (IV) hin zur fünften Übung, die eine emphatisch vorgetragene geistliche Ars amoris ist. Die sechste Übung ist ein (mit 800 Zeilen überlanger) Lob- und Dank-Hymnus, der Gott beinah ausschließlich als Amor deus anspricht, im rhetorisch elaborierten Variationsstil des Jubilus. Die siebte Übung schließlich, eine programmatische Praeparatio ad mortem, ist entlang den sieben kanonischen Stunden strukturiert und dabei zugleich als Gespräch mit der Liebe inszeniert (colloquium cum amore, VII,3).

Wer wird dabei von wem wie serbaut`? Die Ausgestaltung des geistlichen Lebensweges orientiert sich einerseits, wie angedeutet, an den Stationen der monastischen Laufbahn der Nonne (geistliche Umkehr, Profess, Einkleidung, etc.). Anderseits und zugleich werden die bekannten monastischen Wegmarken als Fortschreiten im Raum eines imaginären (allegorischen, inneren) Minneklosters vorgestellt, überwiegend im performativen >Modus` von Gebeten: Hoc modo celebrabis spirituale matrimonium, beginnt die dritte Übung zum geistlichen Brautversprechen (III,1), die die Seele ins göttliche Brautgemach treten (130: introire thalamum) und umgekehrt Gott, den >Geliebten ihrer Gelübde` (339), in der Seele als deren benignus inhabitator wohnen lässt (III,199): im >Modus` von Gebeten, die als Oratio, Antiphona oder Versus angekündigt werden. Schon mit dem Eintreten in die erste Übung ist man im Innern eines Gotteshauses mit Taufbecken, die zweite gibt den Blick auf die gesamte Anlage als Minnekloster und Schule der Liebe frei, und die folgenden Übungen formieren dann gewissermaßen den Innenraum; den Chorraum als Ort des Stundengebets oder das Sakramentshaus als >Brautgemach`, in dessen Innern ein >Marmorgrab ist - damit ist die im Text besprochene zeitliche Erstreckung der vita religiosa zwischen Taufe und Tod auch in der Raumanordnung aufgenommen und zugleich aufgehoben. ${ }^{53}$ Es sind in dieser Art raummetaphorisch ver-

53 Vgl. dazu Ringler [Anm. 4], S. 22 f. Klärend für den Erbauungsstatus der Gebete ist auch die fünfte Übung, die das Exercitium divini amoris ankündigt mit der Aufforderung, einen bestimm- 
doppelte und synchronisierte Anweisungen zum >Aufbau einer spirituellen Vollkommenheit i m und a ls Kloster. In diesem Doppelsinn kann der Text selbst dann mehr sein als bloß `Gebetspraxis`, nämlich Gebets-Anweisung (Einübung) und Medium (Ausübung). Diese Kongruenz zeigt sich auch im Blick auf den Gesamttext: Ziel der `Exercitia spiritualia` ist eine möglichst umfassende Loslösung von der Welt, die bereits zu Beginn als sewiges Wohnen in Gott (I,61) - und das heißt: als sewige Ruhe` des Todes (perpetua requies, I,233) - reformuliert wird. Zu diesem Ziel führe ein >Weg`, auf dem >von Tag zu Tag, von Tugend zu Tugend ‘ fortgeschritten werden soll. Bereits im ersten Satz der >Exercitia ‘ fällt der Blick auf das Weg-Ende: Ut in fine vitae tuae immaculatam babtismalis innocentiae tunicam et fidei christianae sigellum integrum et illaesum domino valeas praesentare..$^{54}$

Jede der sieben Exercitien benennt einleitend knapp das Thema der jeweiligen Wegstation, gefolgt von Ketten von Gebeten (Lob-, Bitt-, Dank-Gebeten etc.), die begleitet werden von Anweisungen zu ihrer richtigen Ausführung (Körperhaltung etc.), wie man das aus der Gebetstraktat-Literatur der Zeit kennt. Der Rezipient muss zur Glaubensstärkung also Aktivität entfalten und die Texte nachsprechen, doch bleibt er mit dieser Aktivität zugleich Objekt und Medium göttlicher Erbauung: $p$ e $r$ t e talis sim in moribus, ut e ff $i$ c i merear templum dei et habitaculum spiritus sanctus $(\mathrm{I}, 58 \mathrm{f} \text {. })^{55}$, und so kann das kontinuierliche >Erbaut`-werden als Tempel Gottes im Verlauf des Textes immer wieder als plötzliches >Versinken reformuliert werden, als je neues Tieferlegen der Fundamente tota promptitudine (II,116). Gertruds `Exercitia sind in diesem Doppelsinn von Übung als Anweisung und Vollzug unterschieden von vorausliegenden oder zeitgenössischen Gebets-Traktaten, auch wenn diese oft gleichfalls raumallegorisch exponiert werden. So entwirft etwa David von Augsburg im Ausgang von der Tempelvision bei Ez 40,1, einen Tempel vollkommenen Betens, $\mathrm{zu}$ dem sieben Stufen führen: Die siben grete, die man vf gat in die porte, das sint siben offenvnge ze der vollecomenheit des gebettis. ${ }^{56}$

ten Tag auszuwählen, an dem morgens, mittags und abends durch die zu rezitierenden Gebete das Herz leer werden solle von ungeordneten Affekten, um sich - im Gebet, qua Gebetsübung mit dem sponsus verbinden zu können (coniungaris deo in or a t i o $n e, \mathrm{~V}, 7$ ), bis sie, zu nichts geworden (annihilata, 39), nach einem Herzenstausch in der `Kammer (178 ff.), in der `Schule der Liebe sich unermüdlich übend in der Kunst der Liebe (in arte amoris, 286 ff.), pro confirmatione amoris (486), dem göttlichen Liebhaber nahekommen solle.

54 >Damit du am Ende deines Lebens Dich dem Herrn makellos zeigen kannst, bete auf die folgende Weise [...].. (Euvres spirituelles [Anm. 4], I,1-3).

55 >Durch dich sei mein Verhalten so, dass ich es verdiene, dass du mich zum Tempel Gottes und zur Wohnstatt des heiligen Geistes machst` (ebd., I,59 f.).

56 David von Augsburg: Die sieben Staffeln des Gebetes, hg. v. Kurt Ruh, München 1965 (Kleine Prosadenkmäler des Mittelalters 1), Z. 76-79, hier Z. 71 f. und 77-79 (über die Stufen >zunehmen- 
Gertruds Gebets-Meditationen sind im Kern eine hymnisch, aber auch in anderen Sprechakten vergegenwärtigte mystische Liebestheologie; Amor deus ist der zentrale Gottesname ${ }^{57}$. Die in der Selbstbeschreibung des Textes ssüße ${ }^{58}$, zugleich theologisch anspruchsvolle Sprache Gertruds ist für jeden modernen Interpreten und Übersetzer des Textes eine Klippe. Wie kann die intellektuelle, affektive und ästhetische Anspannung dieser Liebessprache angemessen beschrieben und vor allem: in ein anderes Sprachmedium übertragen werden? Die bisherige Forschung hat für Gertruds `Exercitia spiritualia` emphatische Wertungen riskiert. Ringler nennt sie ein »Hauptwerk der mittelalterlichen Mystik « ${ }^{59}$, Ruh, der Gertrud erstmals von der »katholisch->barocken«« Patina befreit und als Gründungsfigur barocker Herz-Jesu-Verehrung relativiert hat, zählt ihre Schriften zu den »schönsten, die Frauen verfaßt haben « ${ }^{60}$.

Die Herausforderung, mit der theologischen Substanz zugleich auch die poetische Qualität des Textes zur Geltung zu bringen, ist nicht nur auf der Ebene der Interpretation, sondern schon auf der der Übersetzung groß: die klare, reine ১Süße des lateinischen Iubilus mit seinen Eia o-Anrufungen nicht unmerklich kippen zu lassen in einen für unsere Ohren süßlichen Ton: ১Seele mein` (anima mea), >Herre mein` (domine mi). Im Bereich der Semantik ist die Lage ähnlich riskant: Süßer Jesus, der meine Seele streulich` liebt, mich >gar gut` (II,72 f.) begleitet, >mein Herz, es hanget‘ (VI,571): Das klingt rascher, als dem Übersetzer lieb ist, erbaulich >im altdeutschen Stilı. Eleganz und Prägnanz des Lateinischen sind jedenfalls schnell - und oft unfreiwillig - in der Übersetzung verspielt. Die zitierten Beispiele habe ich Ringlers bis in die Syntax um maximale Äquivalenz bemühter Übersetzung der >Exercitia` entnommen, in der im Ganzen die gelungenen Beispiele überwiegen. Trotzdem zeigen die Zitate, wie heikel es grundsätzlich für religiöse Texte dieser Art ist, den historischen Resonanzraum von

der Minne bis zur 6. Stufe der contemplatio und der 7. Stufe der als praegustatio konzipierten perfectio. In diesem Traktat finden sich auch zahlreiche Instruktionen zu den Modi des Betens (mit dem Mund oder mit dem Herzen, nicht zu schnell oder zu langsam, unabgelenkt, unterbrechungslos, klar artikuliert etc.).

57 Vgl. Michael Casey: Gertrud von Helfta und Bernhard von Clairvaux. Eine neue Einschätzung, in: Cistercienser Chronik 97 (1990), S. 46-69 sowie Ulrich Köpf: Bernhard von Clairvaux in der Frauenmystik, in: Peter Dinzelbacher u. Dieter R. Bauer (Hgg.): Frauenmystik im Mittelalter, Ostfildern bei Stuttgart 1985, S. 48-77.

58 Auch das Titelblatt der Pariser Einzelausgabe kündigt in diesem Sinn an: exercitia nonnvlla pia et rara intime devotionis suauitate castam animam in deum eleuantia (dazu Hourlier/Schmitt [Anm. 4], S. 39 f.).

59 Ringler [Anm 4], S. 10.

60 Ruh [Anm. 5], S. 19. 
Begriffen und Bildern im anderen Sprachmedium hörbar $\mathrm{zu}$ machen - wie ergeht es damit den mittelalterlichen Übersetzern?

An drei Stellen der >Exercitia spiritualia zuliebe - auch eine deutsche Fassung des lateinischen Textes überliefert, eingeleitet mit dem lakonischen Kommentar Haec ita latine ob gratiam lectoris versa sunt. ${ }^{61}$ Die Forschung hat sich, soweit ich sehe, um diese interessanten Stellen bislang nicht gekümmert. Abschließend will ich sie daher, bezogen auf die übergreifende Problemstellung dieses Beitrags, etwas genauer anschauen.

Die ersten beiden deutschen Insertionen finden sich $\mathrm{zu}$ Beginn der zweiten Übung, die die Hinwendung zu Gott (conversio spiritualis) im Akt des Klostereintritts als Vorgang beschreibt, der den Menschen in seiner Gottesliebe serbaut`. Im Anschluss an die oben bereits zitierte einleitende Aufforderung, >Bete darum, dass er sich aus dir ein Kloster der Liebe baue`, folgen ein an Jesus und ein an Maria adressiertes Gebet, und beide Gebete sind als freie, end- und binnengereimte Übertragungen der lateinischen Vorlage in den Kölner Druck mit aufgenommen.

Der erste Teil des ersten Gebets formuliert mit einer Reihe von HoheliedAnspielungen den Klostereintritt als Bitte um Erhörung:

Eia Iesu, cordis mei dilectissime, cum constet nullum spiritualem fructum posse coalescere, nisi tui spiritus perfundatur rore, nisi tui amoris foveatur vigore: utinam igitur ita miserearis mei, ut inter amoris tui brachia me recipias, meque totam tuo spiritu calefacias. En corpus et animam meam, haec tibi trado, ut possideas (II,6-11).

Dieser Teil des Gebets nimmt nicht das angekündigte Bildfeld des (Kloster-)Erbauens auf, sondern das parallele Bildfeld des Bebauens, Blühens und Fruchtbringens. Der zweite Teil dieses Gebets folgt dann zwar der Gebäude-Metaphorik, aber mit vertauschten Subjekt-/Objekt-Rollen (১schließ du, Liebster, auf und lass mich ein`; vgl. Hl 1,3 und 5,2) und kehrt über den Topos der >lebendigen ২ Liebe zum Wachsen und Blühen zurück (wiederum mit einer Hohelied-Anspielung, Hl 2,1):

Dilecte mi, dilecte mi, infunde mihi tuam benedictionem. Aperi mihi et introduc me in suavitatis tuae plenitudinem. Ex corde enim et ex animo desidero te. Oroque te, ut tu solus possideas me. Eia, ego tua et tu meus; fac ut novo semper fervore spiritus in amore tuo vivido crescam, tuaque gratia, quomodo lilia convallium iuxta fluenta aquarum, effloream (II,12-17).

61 Ausgelagert aus der Edition abgedruckt bei Hourlier/Schmitt [Anm. 4], S. 54 f.; zu den deutschen Passagen hier nur wenige Bemerkungen (ebd., S. 43). Ich zitiere diese Passagen nach Ringler, der sie direkt in die Edition übernimmt und auch die metrische Struktur mit abbildet (es sind hier die folgenden Passagen: `Exercitia spiritualia< II,6a-18a und 19a-27a; IV,230a-243a). 
Die deutsche Versübertragung dieses Gebets demonstriert die im Medienwechsel von lingua sacra und Volkssprache verschobenen Bild- und Reimlogiken und Allusionshorizonte. Während der lateinische Text durch dreifache Genitivallegorese (inter amoris tui brachia; meque totam tuo spiritu calefacias; introduc me in suavitatis tuae plenitudinem) die Vorstellung der Liebesvereinigung auf der Deutungsebene je neu unterbricht und auch die Kolonreime anders ansetzt (etwa im Allusionshorizont der lateinischen Hymnik, z. B. im ersten Teil rore: vigore), formuliert die deutsche Übertragung die Vorstellung der Liebesglut bildkohärenter, erstens durch Tilgung von >mit deinem Geist`, zweitens durch Umstellung der Allegorese an eine andere Position im Satz (statt: >mit den Armen deiner Liebe umarmen` heißt es jetzt, im Gleichklang des Binnenreims, sin deinen Armen wahrlich von Liebe erwarmen`), drittens durch Tilgung der Allegorese in suavitatis tuae plenitudinem. Ich zitiere aus der deutschen Version den für diese Beobachtungen relevanten Ausschnitt:

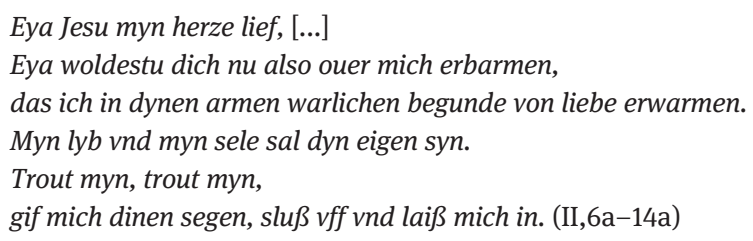

Das zweite, an Maria gerichtete Gebet ist eine Bitte um Fürsprache bei Christus (II,19 ff.), in deren Verlauf das Bildfeld des Bauens aufgenommen wird (>mach, dass ich von Gott in das Minnekloster, in die Schule des heiligen Geistes aufgenommen werde ‘), auf dass - wieder ein Wechsel ins parallele Bildfeld des Bebauens - sie mich zur Frucht ihrer lebendigen Liebe werden lasse. Bei der deutschen (hier: Prosa-)Übertragung fällt wieder auf, dass sie, bei ansonsten hoher Wörtlichkeit, das bildneutrale lateinische obtinere (serreichen`) ersetzt durch das bildanschaulichere serbauen`(bouen), so dass sich auch hier, wie im ersten Gebet, eine verbindlichere Bildkohärenz ergibt.

Die letzte deutsche Insertion im Lanspergius-Druck gehört zur vierten Übung, in der die Seele vor Gott ihre Profess ablegt. In dieser mit wechselnden Sprechakten ganz in der Dialogwelt des Hohenliedes angesiedelten Übung findet sich ein an Jesus gerichtetes Gebet, das den Vorgang der Profess als Übernahme einer veritablen >Liebesregelı entfaltet (amoris regula 230). Wieder verschieben sich mit der Übertragung in die andere Kultursprache die Resonanzräume der Begriffe, wenn die Obhut des Heiligen Geistes (lat. custodia) im Deutschen als hutte (= houte) erscheint (IV,233 und 233a), wenn auch hier amor bzw. caritas jeweils mit minne wiedergegeben werden (234 f. und 236a, 239 und 243a) und das Lateinische die Liebesvereinigung (unio, 238; eynunge, 241a) als 
>kraftvoll-tiefes Einsaugen des Geistes durch den Geist Gottes vorstellt, was im Deutschen, gegenbildlich zu Erbauung, als >plötzliches Versenken ‘bzw. >Auf den Grund Senken wiedergegeben wird: Absorbe spiritum meum tuo spiritu tam valide tamque profunde, ut vere tota sepeliar in te [...]: Sencke mynen geyst so vaste/in dynem geiste tzo grunt in einem haste,/das ich werlichen in dich werde begraben [...] (236 f. und 238a ff.).

Aufschlussreich für die von der Forschung ungeklärte, schwer auflösbare Frage nach den Umständen der lateinisch-deutschen Übertragung ist an dieser Stelle die Beobachtung, daß im weiteren Verlauf der vierten Übung, mehr als hundert Zeilen später, bei der Vergegenwärtigung der Kommunion als eucharistischer unio (IV,312 f.) die Liebesvereinigung als Versinken im Abgrund beschrieben wird (Rumpe super me omnes fontes magnae abyssi, 335), was mit dem Appell fortgesetzt wird: Absorbeat me profundum tuae charitatis (336): >Es sauge mich auf (und verschlinge mich) die Tiefe deiner Liebe`. Ob die deutsche Übersetzung von absorbe im oben zitierten Vers (〉Lass in den Grund versinken`) von dieser späteren Passage aus zu denken ist, ist schwer $\mathrm{zu}$ entscheiden. In jedem Fall nimmt das Versenktwerden im Abgrund des Meeres hier noch eine überraschende metaphorische Wendung - durch einen >Liebestrankı: Vitam mihi auferat tui amoris poculum. [...] et perficiat in me gloriosam mortem vitalis amoris (342 ff.).

Man muss von hier aus nicht zum weit entfernten Gottfried'schen >Tristan gehen, um dennoch festhalten zu können: Die Fähigkeit der mittelalterlichen Theologie und Frömmigkeitspraxis, »Heterogenstes $\mathrm{zu}$ integrieren ${ }^{62}$, ist groß, zumal für den semantisch wie epistemisch hochintegrativen Liebesdiskurs. Klärungsbedürftig bleibt dabei von Fall zu Fall, bei aller evidenten Inklusionsmacht der beiden (höfisch-christlichen) kulturellen Hochsemantiken, ob das, was in der Selbst- bzw. Außenwahrnehmung als >Kompromiss` gilt, lediglich die selbstverständliche Eigenresonanz einer von Anfang an vielstimmigen Kultur ist oder aber, jenseits unauffälliger Assimilierung, ein poetologisch signifikantes oder auch inhaltlich brisantes Konfliktpotential. Meine Überlegungen blieben demgegenüber ganz im Paradigma innerchristlicher Spannungen.

Anhand kleiner Ausschnitte wollte ich zeigen, dass das, was im Spätmittelalter als unhintergehbare Widersprüchlichkeit einübbarer >Erbauung`nicht unterschätzt werden sollte, sich vielfältig und ganz unterschiedlich artikuliert: im Spannungsfeld von Disziplinierung (Zensur oder spiritueller Selbstdisziplinierung) und Überschreitung, auch im Spannungsfeld von Volkssprache und Latein,

62 Jan-Dirk Müller: Wie christlich ist das Mittelalter oder: Wie ist das Mittelalter christlich? Zum >Herzmaere` Konrads von Würzburg, in: PBB 137 (2015), S. 396-419, hier S. 398. 
mit je verschiedenen Eigendynamiken kunstsprachlicher Überformung, allegorischer und spekulativer Diskursivierung.

Im Ausgang von einer spezifisch umgesetzten `Erbauung، führen Gertruds `Exercitia spiritualia in weitreichende Aporien religiöser Vollkommenheitsansprüche. Auf dem in sieben Stationen einzuübenden Weg der Seele zum >Haus Gottes` (VII,652-656) muss die Seele zugleich selbst Haus werden, genauer: als claustrum amoris serbaut` werden. Der Weg hat den Tod zum Ziel, räumlich gesprochen: das im Liebeskloster gebaute Marmorgrab, aber auch das Sterben kann seingeübt` werden, durch eine ars amoris oder, etwas überraschender, einen Liebestrank. So ist nur konsequent für die Seele alles Erbautwerden von Anfang an ein Versinken, so wie umgekehrt in der letzten Übung das imaginierte Sterben ein transitus zum (ewigen) Leben. >Möge mir der Übergang sicher sein (securum habeam transitum, VII,363 f.) - die sieben >Exercitia spiritualia s sind nichts anderes als eine Antwort auf diesen prinzipiell unsicheren Punkt. Trotzdem bleibt auch der Übergang ein exercitium - ein Grundwiderspruch, aus dem Aufstiegsmodelle dieser Art ihr spirituelles und poetologisches, ihr unverwechselbar >erbauliches` Profil gewinnen. In den `Exercitia`stellen die Gebetsketten mit minimalen Verschiebungen Synchronisierungen her. Natürlich ist das im Vergleich mit Eckharts Predigten ein anderer Fall zeittranszendenter Heilsvergegenwärtigung unter anderen Gattungsbedingungen, aber wenn Gertruds serbauliche` Übungen im raschen Wechsel thematischer, bildlicher und klanglicher Responsionen das Erbautwerden als Gottes Minnekloster, Liebesschule und Grabmal von der ersten Übung an engführen, stellen sie auf ihre eigene, kontemplativ-konnotative Weise eine emphatische Kontemporalität her, die, wie Eckharts Abgeschiedenheit auch nicht, keine sbloß figurale oder präfigurale sein will, sondern - qua Gebetsübung - eine Überschreitung. 